Miroslav GUTTEN

Daniel KORENCIAK

Matej KUCERA

Milan SEBOK

Marek OPIELAK

Pawel ZUKOWSKI

Tomasz N. KOLTUNOWICZ

\title{
MAINTENANCE DIAGNOSTICS OF TRANSFORMERS CONSIDERING THE INFLUENCE OF SHORT-CIRCUIT CURRENTS DURING OPERATION
}

\section{EKSPLOATACYJNE DIAGNOSTYKITRANSFORMATORÓW UWZGLĘDNIAJĄCE PRAQDY ZWARCIA PODCZAS PRACY}

\begin{abstract}
Article presents theoretical, simulation and experimental analyses of possible effect of short-circuit forces on the transformer windings. The first part of the article is focused to the establishment and activity radial and axial forces during short circuit. It shows dimensions, direction and of course caused mechanical stress. Equation shows basic dependencies of these mechanical forces created in the transformer windings. The last part of the article is focused on the simulation method which shows the mechanical stress caused by the short-circuit currents on transformer. The paper presents experimental methods of diagnostics for analysis of the short circuit on transformer windings.
\end{abstract}

Keywords: transformer, diagnostic, diagnostic system, transformer windings, frequency method.

\begin{abstract}
Artykut przedstawia teoretyczna, symulacyjna i doświadczalna analizę ewentualnych wpływów pradów zwarciowych na uzwojenia transformatorów. Pierwsza część artykułu koncentruje się na powstaniu i działaniu promieniowych i osiowych sit podczas zwarcia. Przedstawia rozmiary, kierunek i oczywiście powstate naprężenia mechaniczne. Równanie pokazuje podstawowe zależności sił mechanicznych powstałych w uzwojeniach transformatora. Ostatnia cześśc pracy dotyczy metody symulacji, która przedstawia naprężenia mechaniczne spowodowane przez prady zwarciowe na transformatorze. Artykut przedstawia eksperymentalne metody diagnostyki do analizy wptywu zwarcia na uzwojenia transformatora.
\end{abstract}

Stowa kluczowe: transformator, diagnostyka, diagnostyczny system, uzwojenia transformatora, metoda częstotliwościowa.

\section{Introduction}

The worst mechanical effects acting on the transformer are under the sudden short-circuit. Since the currents flows through the windings in the case of short-circuit are enormously, forces generated by these currents are also large and in many cases exceed the value of the maximum mechanical strength of windings or other parts of the transformer. Because of the transient and dynamics entity of this phenomenon the solution is very difficult.

It is therefore necessary, in the absence of scientific and research potential in distribution and transmission organizations (e.g. power plants, heating plants), to achieve the objectives of the proposed activities, i.e. in-depth analysis of undesirable impacts of short-circuit currents on the state of transformers, design of modern methodology of measurements and its verification, and design of a new integrated system of diagnostics with the possibility of analysis and classification of possible failures by short-circuit impact on power transformers.

Except the winding faults (inter-turn short-circuit, short time connection with the tank) it could lead to the tank damage because of the arc pressure. The direct cause of the acting forces on windings is the action of the magnetic field with current paths. In the case of the transformer it is the field of the leakage flux. Normal conditions, when the currents in the transformer do not reach the rated ones, the forces acting on the windings are generally small. On the contrary, the short-circuit currents reach the values which are multiple of the rated ones; these forces could be dangerous for the windings and fixing construction.

Forces in transformer windings can be radial (transverse) and axial (lengthwise), since these two components of the force can be calculated and analyzed independently. Also, the two components have influence on different parts of the total transformer and it is necessary to obtain the two components for design purposes. The nomenclature axial and radial is applicable to concentric wound core type transformer.

Action of the forces on the windings could be separated to the radial and axial forces (Fig. 1). Both of these forces exist not only in the short-circuit conditions but also in the rated condition [3].

\section{Theory of radial and axial forces}

Radial forces are generated by the interaction of the current and the axial component of the leakage flux density. They tend to squeeze the inner winding and burst the outer winding. The calculation of radi- 


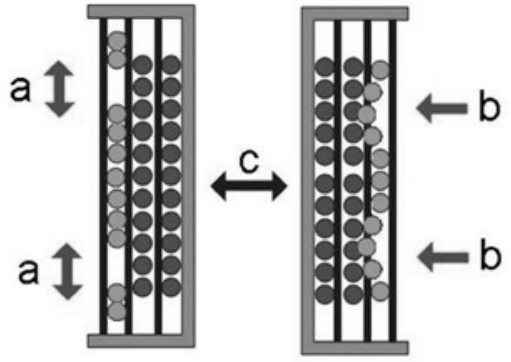

Fig. 1. Forces affect the winding of power transformer during short-circuit: $a$-axial effects, $b$ - radial effects, $c$-winding in normal state

al forces does not at present much difficult since the axial component of the leakage flux density is calculable fairly accurately.

Calculation of the stresses due to this force acting on the conductors is more complex, especially for inner windings. The compressive strength of winding is influenced by the radial thickness of conductors, its work hardening strength, number of blocks per circle and winding dimensions. Similarly, the outer winding experiences outward radial force which results in tensile stress. The tensile strength of winding depends on the work hardening strength of the conductors.

Radial forces are as a result of an effect of the longitudinal field - parallel to the axis of winding of the transformer. These forces stretched the outdoor windings and compress the internal winding, thereby increase the air space between windings. The sum of the radial forces is active to additional space between the windings - the outdoor primary winding has been moved to the outside space [3].

Axial forces are those that act in the axial direction and are generated by the interaction of the current and radial component of the leakage flux density. These forces are flux result which has made by the short-circuited conductor.

These forces can deform the windings in the lengthwise direction, and their overall addition operates on the coil of clamping ring and other clamping elements. The computation of these forces causes big problems since the radial element of the leakage flux density is difficult to compute exactly. When ampere-turns are exactly aligned so that the leakage flux pattern is symmetrical, then the leakage field is axial over the major part of the coil height. But due to the flux lines dispersing in the radial direction in the vicinity of the winding ends, the axial flux density tends to decrease, and the resultant flux density at the ends can be resolved into the radial component causing axial forces. These axial forces are unequally distributed between the outer and inner winding, due to the presence of core.

The axial forces at the top and bottom are in opposite directions as the currents are in the same direction. In case the ampere-turns are perfectly balanced and the leakage flux pattern is symmetrical, the resultant force on the winding would be zero. Any axial displacement between the magnetic centres of HV and LV windings will result in forces, which will increase the displacement $[5,10]$.

\subsection{Forces calculation}

Based on theoretical analysis and model measurements it is needed to create a computing environment short-circuit forces. Based on this diagnostic approach it will be necessary to determine the possible effect of the devices and the insulation and mechanical condition of transformers.

The basic equation for the calculation of any electromagnetic force is:

$$
\vec{F}=I(\vec{l} \times \vec{B})
$$

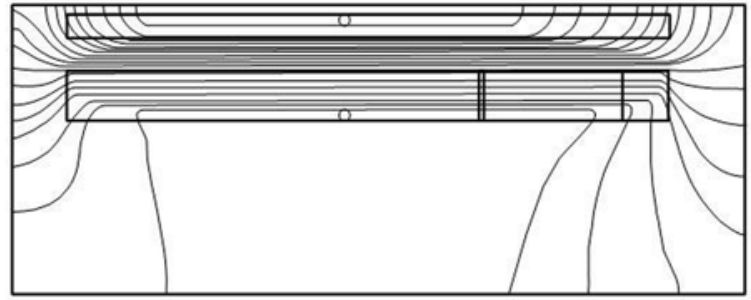

Fig. 2. Typical leakage flux pattern in a two winding transformer

where $\vec{B}$ is flux density due to leakage flux at mean radial depth of winding, $\vec{l}$ is the conductor length and $I$ is the current during shortcircuit. An examination of equation (1) shows that, since $\vec{F}$ is the cross=product of $I$ and $\vec{B}$, a radial flux will give rise to axial force while an axial flux will give rise to radial force. The right side of equation (1) involves only three quantities, $I, \vec{B}$, and $\vec{l}$. Of these, the current $I$ and the length $\vec{l}$ are known exactly. The calculation of the transverse and lengthwise components of the leakage flux density is the most difficult task and forms the crux of the problem.

\subsection{Calculation of the radial forces}

A simple formula for the average radial force can be derived by evaluating the axial component of the leakage flux density and applying equation (1). An assumption is made that all the leakage flux is axial only and passes between top and bottom yokes in straight lines. This assumption is also made in calculation of leakage reactance and will lead to a slightly higher value of radial force. The calculation of flux density of radial depth on transformer windings is given by:

$$
B=\frac{1}{2} \cdot \quad 0 \frac{N \cdot i_{\mathrm{p}}}{L_{\mathrm{u}}} .
$$

The average value of the radial force after the substituting equation (2) to equation (1) given by:

$$
F_{\mathrm{R}}=\frac{1}{2} \cdot \mu_{0} \cdot \frac{\left(N \cdot i_{\mathrm{p}}\right)^{2}}{L_{\mathrm{u}}} \cdot \pi \cdot D_{\mathrm{m}},
$$

where $\mu_{0}$ is a permeability of vacuum, $N$ is number of turns, $i_{\mathrm{p}}$ is an asymmetric peak of the short-circuit current, $L_{\mathrm{u}}$ is height of the winding and $D_{\mathrm{m}}$ is a mean diameter of main inter-coil duct.

Due to the assumption that all the flux is axial in nature, equation (3) will result in a force larger than that due to any other formula. It is used in all stress calculations and in the design of windings.

The maximum force per turn will occur at the inner turn of innermost layer of the outer winding and the outer turn of the inner winding and will be given by:

$$
F_{\mathrm{R} \max }=\frac{F_{\mathrm{R}}}{N} .
$$

If the turn experiencing this force has small radial dimension and is unsupported by any adjacent turns, the stress calculations are done using equation (4). Otherwise the average force of equation (3) is used for stress calculations. Graphical interpretation of the radial forces 
acting on windings with interpretation of the symbols from equations (2) and (3) is shown in the Fig. 3.

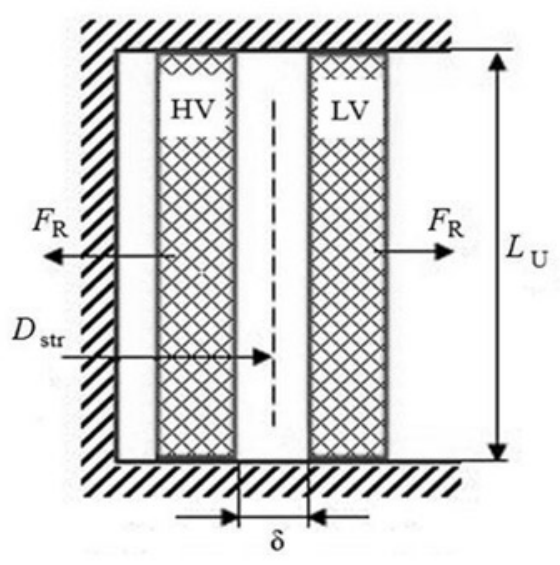

Fig. 3. Acting of the radial forces

\subsection{Calculation of the axial forces}

The electromagnetic forces arising due to a short circuit are oscillatory in nature, and act on an electric system immersed in oil and consisting of winding conductors, insulation components and clamping structure. Such forces, dynamically transmitted to various parts such as conductors, end supports, press plate, and clamps may be quite different, both in magnitude and in wave-shape from the internally generated electromagnetic forces depending on the relationship between the excitation frequency and the resonant frequency of the system.

When evaluating axial forces, winding misalignments, caused by workshop tolerances need to be considered. The design force calculations are performed both, for the symmetrical configuration and the displaced configuration of windings. In case of a symmetrical winding arrangement in axial direction having uniform current distribution, there is no resulting force against yoke, and the winding tends to be compressed in the axial direction only. Different yoke distances and tapping in the main winding and uneven current distribution in the axial direction can cause the force integral to reach a final value greater than zero. Two cases may occur. In the first case, the residual force is towards the bottom yoke. In the second case has a negative value at the bottom yoke, thus resulting residual force towards to top yoke.

While a simple formula could be obtained for radial forces, such is not the case for axial forces because must be taken into account the value of ampere-turns causing the radial leakage flux. An approximation to the ampere-turns causing radial leakage flux is the residual ampere-turns caused due to tapings, gaps in windings and unequal winding heights. This is only an approximation, since even perfectly

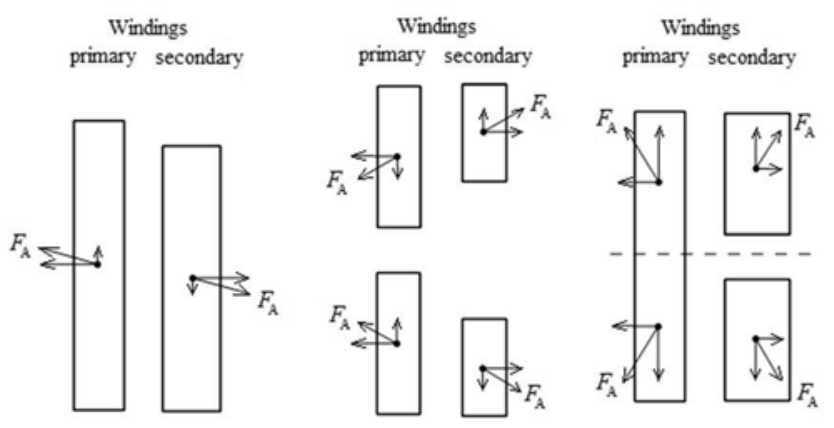

Fig. 4. Unbalanced windings causing axial forces balanced windings will still have fringing of flux at the coil ends, giving rise to radial component of flux. The approximation is on the conservative side, since the peak value of the residual ampere-turns are used for calculations. Fig. 4 shows examples of unbalanced windings causing radial forces.

The flux lines are influenced by the core legs, yokes, the clamping structure, the tank walls and all other magnetic structures within the tank, and follow quite complex paths for closure. An exact evaluation of the effective length of path is extremely difficult, if not impossible.

For an acquisition of the empirical formulas various attempts were made. Hrabovcová V, et al. [1], Fergestad [2] and Knaack [8] proposed various methods for effective length evaluation but the simplest of all these approaches is that of Waters [12] which considering that there is an unbalance of ampere-turns.

The mean radial flux is given by:

$$
B_{\mathrm{R}}=\frac{1}{2} \cdot \mu_{0} \cdot a \cdot \frac{N \cdot i_{\mathrm{p}}}{l_{\mathrm{eff}}},
$$

where $a$ is per unit unbalance between windings and $l_{\text {eff }}$ is the active length of track of short-circuit current.

Substituting (5) to the equation (1) and the follow fitting could be reached formula for axial force calculation:

$$
F_{\mathrm{A}}=\frac{1}{2} \cdot \mu_{0} \cdot a \cdot\left(\mathrm{N} \cdot i_{\mathrm{p}}\right)^{2} \cdot \frac{\pi \cdot \mathrm{D}_{\mathrm{m}}}{l_{\text {eff }}}
$$

where $\pi \cdot \mathrm{D}_{\mathrm{m}} / l_{\text {eff }}$ is the residual ampere-turns factor that values are stated in [12] for various ampere-turns configuration.

\section{Simulation analysis}

Simulation analysis involves calculation of the distribution transformer $22 / 0.4 \mathrm{kV}$ model in a no load and short circuit conditions using COMSOL Multiphysics [6]. Second step is an approximation of the sinusoidal waveforms by calculating the values of the voltage and current using MATLAB Curve fitting tools. Next step consist the determination of the values of asymmetric peak of the short-circuit currents for short circuit directly behind the transformer, short circuit in the distribution box and short circuit on the end of the $1 \mathrm{~km}$ length cable. The final step is a calculation of the forces acting on the windings and their application to the modeled LV winding order to observe of their deformation and of the value of stress pressure. By applying the formulas for transformer measurements from [3] it is possible to calculate the values of equivalent circuit elements (Tab. 1).

Table 1. Values of the equivalent circuit elements

\begin{tabular}{||c|c|c|c||}
\hline \multicolumn{2}{|c|}{ No load } & \multicolumn{2}{c|}{ Short-circuit } \\
\hline$I_{\mu \mathrm{R}}$ & $4.386 \mathrm{~A}$ & $R_{1}$ & $40.160 \Omega$ \\
\hline$I_{\mathrm{feR}}$ & $1.326 \mathrm{~A}$ & $R_{2}$ & $0.013 \Omega$ \\
\hline$X_{\mu \mathrm{R}}$ & $52.660 \Omega$ & $X_{\sigma 1}$ & $91.016 \Omega$ \\
\hline$R_{\mathrm{feR}}$ & $174.130 \Omega$ & $X_{\sigma 1}$ & $0.030 \Omega$ \\
\hline
\end{tabular}

\subsection{Determination of the short-circuit currents}

For the forces calculation is necessary to determine the value of the asymmetric peak of the short-circuit current. Program is structured for three different locations (points) of the short circuit (behind the transformer, in the distribution box, on the end of the cable). Fig. 5 shows connection diagram in MATLAB. 


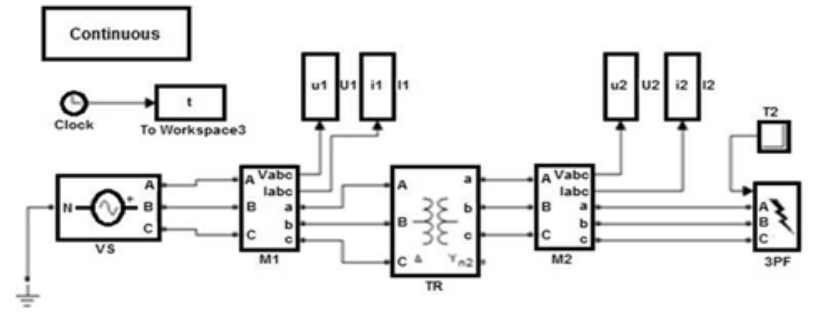

Fig. 5. Short circuit directly behind the transformer in MATLAB Simulink

Parameters of the circuit behind the transformer for different locations of short circuit are written in Tab. 2

Table 2. Impedance parameters of the short circuit behind the transformer

\begin{tabular}{|c|c||}
\hline Point of the short circuit & Circuit parameters \\
\hline Behind the transformer & $R=0 \Omega, X=0 \Omega$ \\
\hline $\begin{array}{c}\text { In the distribution box }(15 \mathrm{~m} \mathrm{Cu} \\
\left.240 \mathrm{~mm}^{2}\right)\end{array}$ & $R=0.090 \Omega / \mathrm{km}, X=0.068 \Omega / \mathrm{km}$ \\
\hline $\begin{array}{c}\text { On the end of the cable }(1 \mathrm{~km} \mathrm{Cu} \\
\left.120 \mathrm{~mm}^{2}\right)\end{array}$ & $R=0.181 \Omega / \mathrm{km}, X=0.069 \Omega / \mathrm{km}$ \\
\hline
\end{tabular}

Instantaneous value of short-circuit currents in LV windings is shown in Fig. 6. Values of the asymmetric peak of the short-circuit currents for different points of short circuit are shown in the Tab. 3 .

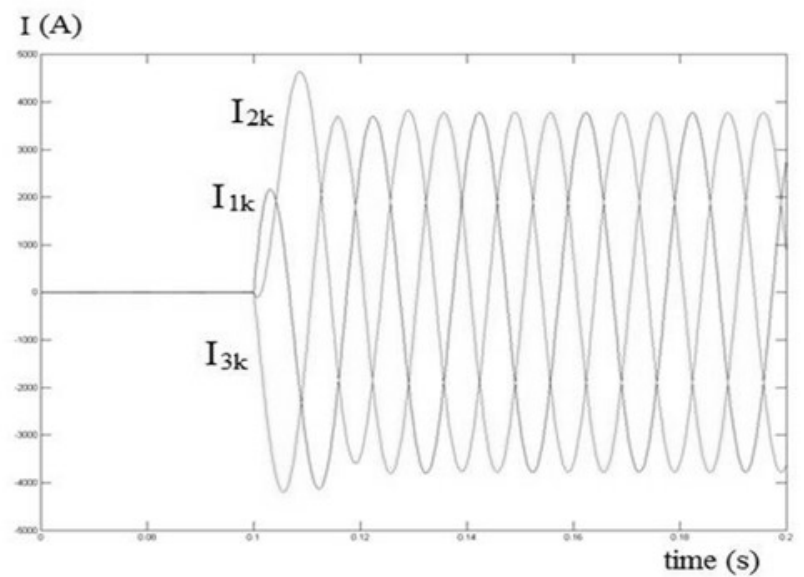

Fig. 6. Wave-shape of the short circuit behind the transformer

Since the short-circuit current has the largest value in phase B, the calculation of the forces is carried out with those most unfavorable values. An asymmetric peak of short-circuit current values in phase B for each point of the short circuit are shown in the Tab. 3 .

\subsection{Simulation in considering of the short-circuit currents}

Calculation of the radial and axial forces for single layer of the $\mathrm{LV}$ winding is made by using the equations (3) and (6), where $N$ is the turn number, $i_{\mathrm{p}}$ is an asymmetric peak of the short-circuit current, $L_{\mathrm{u}}$ is the height of the winding $l_{\text {eff }}$ is active length of track of transverse leakage flux, $a$ is per unit unbalance between windings and $D_{\mathrm{m}}$ is diameter of main inter-coil duct.

Values substituted to the equation for calculating of the forces are shown in the Tab. 4. The calculated values of the radial and axial forces for $5 \%$ unbalance of the windings are shown in Tab. 5 .

Fig. 7 shows the resulting pressure stress and permanent deformation of the winding due to radial force. Simulation of the radial
Table 4. Values fitted to the equations (3) and (6)

\begin{tabular}{|c|c|}
\hline Variable & Value \\
\hline Conductor cross section & $60 \mathrm{~mm}^{2}(12 \cdot 5)$ \\
\hline Inner radius of the thread & $141.4 \mathrm{~mm}(100 \cdot \sqrt{2})$ \\
\hline Number of turns in layer & $32(64 / 2)$ \\
\hline Height of the winding & $508.0 \mathrm{~mm}(12 \cdot 32+4 \cdot 31)$ \\
\hline $\begin{array}{c}\text { Effective path length of radial } \\
\text { leakage flux }\end{array}$ & $112.8 \mathrm{~mm}(0.222 \cdot 508)$ \\
\hline Mean diameter of thread & $317.8 \mathrm{~mm}(2 \cdot 100 \cdot \sqrt{2}+35)$ \\
\hline
\end{tabular}

force acting is calculated for the maximum value of the force (short circuit directly behind the transformer) applied to single layer of the LV winding.

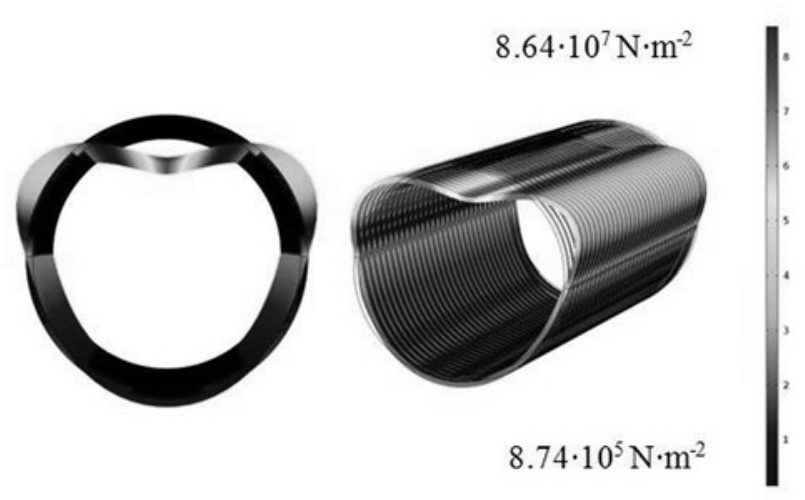

Fig. 7. Permanent deformation and distribution of the pressure stress due to radial force

Fig. 8 shows the resulting pressure stress and permanent deformation of the winding due to axial force. Acting force is also proportional to the maximal current for the short circuit directly behind the transformer.
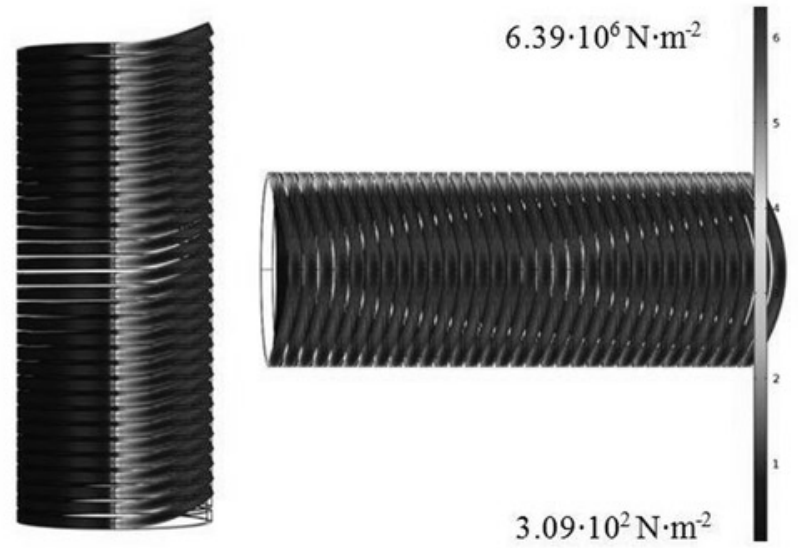

Fig. 8. Permanent deformation and distribution of the pressure stress due to axial force for $5 \%$ per unit unbalance between windings

The dependence of the axial force on the unbalance between windings is shown on the Fig. 9. It also shows the necessity of precisely attachment of all windings in order to prevent of the per unit unbalance. Even at small values of unbalance greatly increases size of the axial force. 


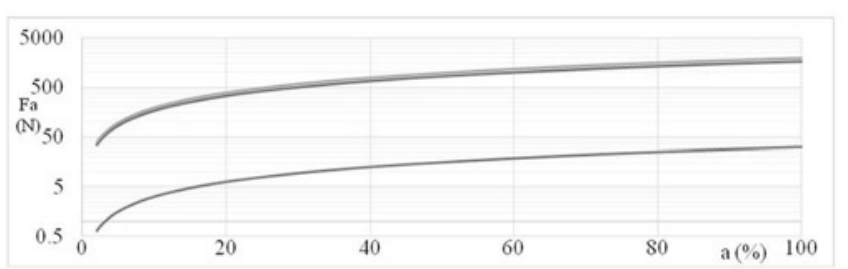

Fig. 9. Dependence of the axial force value on per unit unbalance between windings

\section{The current experimental methods of diagnostics}

The biggest problem of today's energy transmission and distribution works is that the measured data from the diagnostic measurements are not adequately studied, since there is no scientific and research base. Therefore, to assess technical condition of equipment, for example, in terms of their residual lifetime is a major problem in deciding on the early decommissioning. In an unpredictable moment, a failure may occur, and the consequence may be the power failure for a long time. In an unpredictable moment a failure may occur, and as a consequence the power failure for a long time. Even when using expensive commercial measuring devices, it is necessary to deeply analyze the measured data in relation to knowledge of exposure to adverse effects on specific electrical equipment. Thus achieving the objectives of this project may help to clarify the adverse effects and propose new diagnostic procedures through which it can be detected forthcoming failure of the device, and to suggest certain steps in advance (e.g. the early exchange for a new device) [11].

With regard to the effects of short-circuit currents, over-currents and other phenomena which damage winding and magnetic circuit, the following measurements will be realized at disconnected transformers:

- measurement of frequency characteristics by the SFRA method (Sweep Frequency Response Analysis),

- measurement of time response of windings by the high voltage impulse source (impact test),

- measurement of parameters of windings at short circuited state,

- combination of diagnostic methods according to the proposed measurement procedures.

The use of different diagnostic methods and measurement procedures enables to make measurements also at connected transformers. These are thermography measurements, and monitoring of changes in electromagnetic radiation of transformers and their influence on measure of interference with other devices, such as telecommunication or data devices.

At failure, e. g. as a result of shift or inter-turn short-circuit at the winding of a transformer, the electromagnetic interference with other electrical apparatuses may change.

That is why the following measurements at connected transformers will be realized with the use of experimental technique:

- thermography measurement,

- measurement with the regard to electromagnetic interference of distribution apparatuses,

- additional measurements, or their combination, according to the proposed measurement procedures.

Because of these measurements at transformers we can detect the effects of short-circuit currents, over-currents and other phenomena, which damage winding and magnetic circuit of the transformer, without its dismantling and subsequent investigating of failures, which is time-demanding [6].

Measurement of frequency characteristics by the SFRA method, measurement of time response of windings by the high-voltage impulse source and measurement of parameters of windings at short- circuited state belong to diagnostic methods of transformers without dismantling. During measurements there is no need of intervention to the construction of measured machine, and they are performed at disconnected transformer [13].

\section{Experimental analysis of the distribution transform- er}

On the basis of applied algorithms and procedures realized in the first phase of solution in the paper, there were determined individual diagnostic methods and measuring techniques, for measurements on distribution transformer $22 \mathrm{kV} / 0.4 \mathrm{kV}$ with defect on the high voltage phase A (Fig. 10). Our task was to compare the sensitivity of the two methods - SFRA method and high voltage impulse source by impact test.

The SFRA method and by the measurement of time response method (impact test) enable to determine the time response or frequency response of characteristic quantities of transformers. Measurement of a response in the time domain means finding out of time course to a certain voltage pulse at the input of windings. Measurement of a response in the frequency domain consists finding out of amplitude (and phase in degrees) of a response to the harmonic voltage with a variable frequency at the input of winding. Whereas the response found out in the time domain is a record of time course of voltage, the response found out in the frequency domain is dependence of the amplitude response to frequency [9].

\subsection{Analysis of the transformer by SFRA}

The distribution transformer measurement applies for a setting up of the frequency scale at least $20 \mathrm{~Hz}$ to $2 \mathrm{MHz}$ at output impedance 50 $\Omega$ and source voltage $0.2-20 \mathrm{~V}_{\mathrm{pp}}$ using Megger FRAX 150 (Fig. 11). The measurements were performed in a no-load and short-circuited state according to established standards.

During no-load test is detected a mechanical state of tested winding and ferromagnetic core of transformer. The measured curves are typical for the most important information about changes in the transformer core, which are visible in low frequencies and higher frequencies refer to problems into winding movements or turn-to-turn fault regarding to short-circuit forces [4].
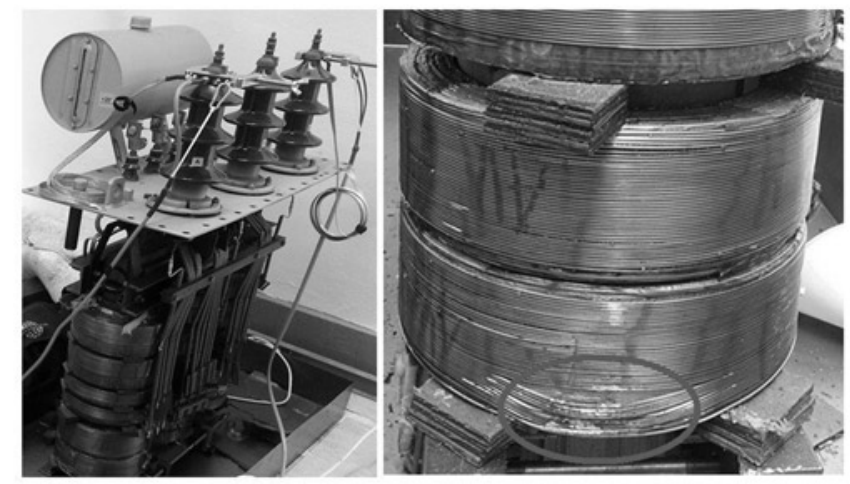

Fig. 10. Distribution transformer 22/0.4 kV under the test in HV laboratory with defect on the A phase

Difference between behaviours at low frequencies about to $1 \mathrm{kHz}$ it can indicate problems due to movements of transformer core, because it developed its resistance component. Difference between behaviors at middle frequencies about to $100 \mathrm{kHz}$ it can indicate problems due to deformation and damage of transformer core, because it developed inductive component of coils. At high frequencies about from $100 \mathrm{kHz}$ it can indicate problems due to damage of winding 


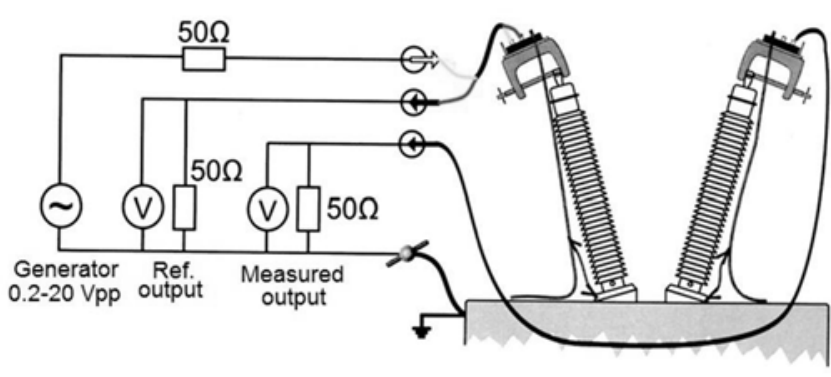

Fig. 11. SFRA test connection using FRAX 150

insulation or contact resistance of transformer taps, because it developed capacitance component.

During the short-circuit measurement mainly the winding state in primary or secondary part of transformer is detected. There tests notifies reliably of deformation of inner winding and its movement as a result effects of short-circuit forces.

The using of analysis of phase curve depending on frequency is suited for more complete evaluation of winding state. This analysis enables to assess the processes of winding deformation during the particular short-circuit effects.

In the Fig. 12 it can be seen the comparison of measurement curves of the impedance attenuation $(\mathrm{dB})$ depending on frequency in a state of no-load and short-circuit at the connection primary phase A-C of measured transformer, and consequently in the Fig. 13 comparison of the curves of measurement the phase (in degrees) depending on the frequency of the same connection.

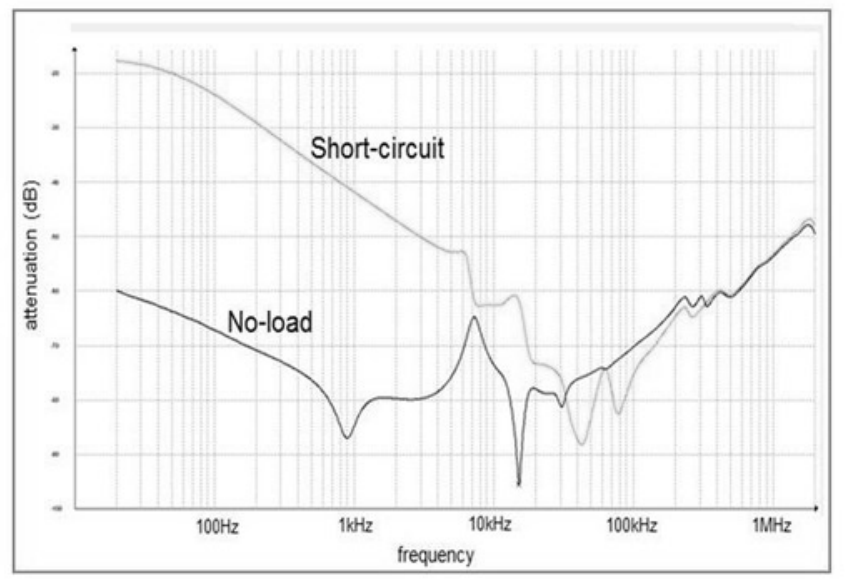

Fig. 12. Measurement of impedance attenuation

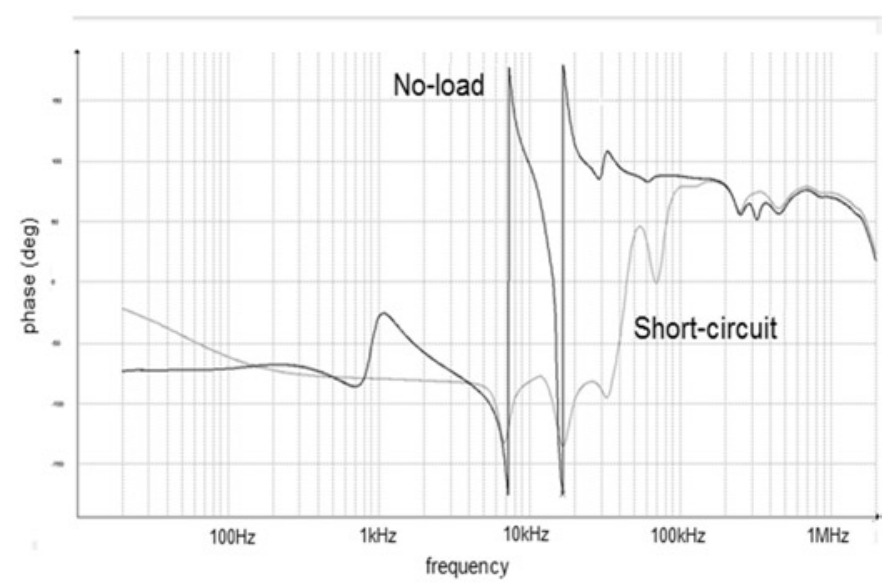

Fig. 13. Measurement of phase in degrees

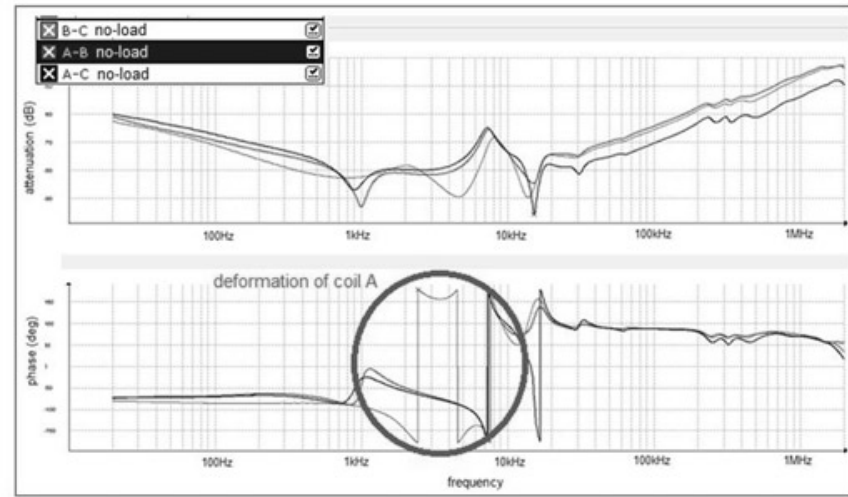

Fig. 14. Comparing the measurement of attenuation and phase in depending on the frequency in no-load test

According to comparison both figures it is highly visible difference of curves in depending phase from frequency in the Fig. 13, thereby increasing the analysis sensitivity of the transformer state.

Fig. 14 shows similar and significant difference. An inter-thread deformation on the coil A is most sensitive displayed by dependence of the phase on the frequency (about $1-10 \mathrm{kHz}$ in lower figure). It should be noted that if the transformer windings are star connected, different curve between phases $\mathrm{B}-\mathrm{C}$ means damage of other phase coil, thus coil A.

Analysis of the measured results is possible to carry out by normalized mathematical standard „DL/T 911-2004”. This calculation method mathematically analyses differences between two curves (sequences) using relative factor $R_{\mathrm{xy}}$ in equations (7), (8) and (9).

Calculation of the two sequences standard variance:

$D_{x}=\sum_{K=0}^{N-1}\left[X(k)-\frac{1}{N} \sum_{K=0}^{N-1} X(k)\right]^{2} D_{Y}=\frac{1}{N} \sum_{K=0}^{N-1}\left[Y(k)-\frac{1}{N} \sum_{K=0}^{N-1} Y(k)\right]^{2}$.

Calculation of the two sequences covariance:

$$
C_{X Y}=\frac{1}{N} \sum_{K=0}^{N-1}\left[X(k)-\frac{1}{N} \sum_{K=0}^{N-1} X(k)\right]^{2} \cdot\left[Y(k)-\frac{1}{N} \sum_{K=0}^{N-1} Y(k)\right]^{2}
$$

Calculation of the two sequences normalization factor covariance:

$$
L R_{X Y}=\frac{C_{X Y}}{\sqrt{D_{X} D_{Y}}} .
$$

Finally, from equation (9) is determined relative factor $R_{\mathrm{xy}}$.

The result of the analyses in no-load conditions according equations (7) till (9) is value of the relative factor $R_{\mathrm{xy}}=0.35$ in the frequen-

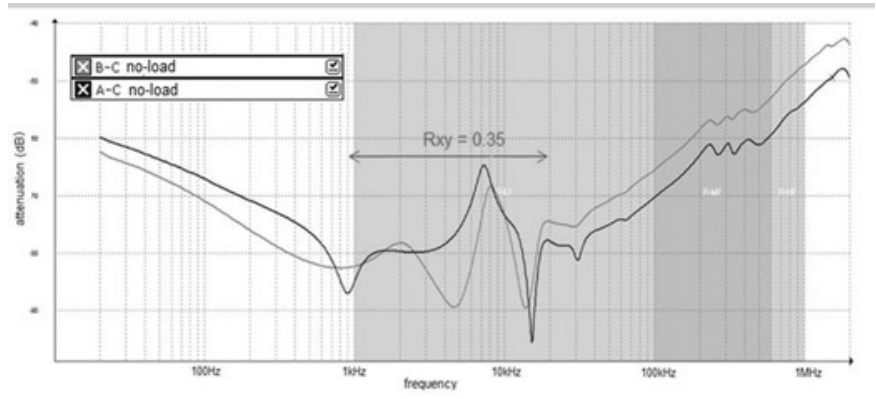

Fig. 15. Frequency analysis of deformation coil $A$ between the winding-phase $A-C$ and $B-C$ 
cy range from $0.9 \mathrm{kHz}$ to $20 \mathrm{kHz}$ (Fig. 15), where prevails value of the inductive part which is dependent on the geometry of the winding.

The finding above represents deformation anomaly due to interthread short-circuit, thus damage of the coil A and threat of the transformer operation (Fig. 10 - visual defect).

\subsection{Analysis of the transformer by impact test}

Impact test is commonly used for testing of the insulation among threads of coils or windings themselves and for searching of the attenuated winding sections of electrical machines. This test allows detecting early stages of the winding faults. Short time voltage pulses are applied to the coil in order to create a voltage gradient across the whole wire of the winding. This gradient produces an immediate voltage stress among the threads.

In the time intervals between pulses the coil responds by damping oscillations with sinusoidal shape. Each coil has unique nature of the respond which could be analysed by oscilloscope. Wave shape is affected by transient circuit dependent on the coil inductance and internal capacity of the pulse generator. When inter-thread occurs, an inductance decreases, thereby increases the frequency of the respond signal.

Fig. 16 shows a comparison of time-domain curves from impulse test measurement on the distribution transformer, where is possible to

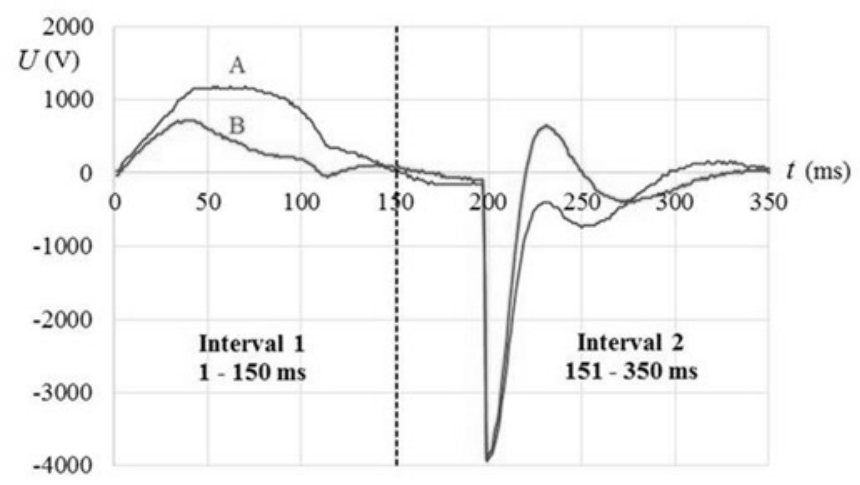

Fig. 16. Analysis of transformer coils by impact test

observe decreased time period from $9 \mathrm{~ms}$ to $12 \mathrm{~ms}$ caused by defect of the coil. Potential amplitude decrease is caused by the change of the circuit resistance and capacitance due to damaged conductor and winding insulation. The comparison is carried out on the windings of two phases, where phase A is affected by inter-thread short circuit and phase B is without fault.

In order to determine condition of windings it is necessary to understand that particular curves overlap when windings are identical and not damaged. Mutually shifted curves indicate damage on one of

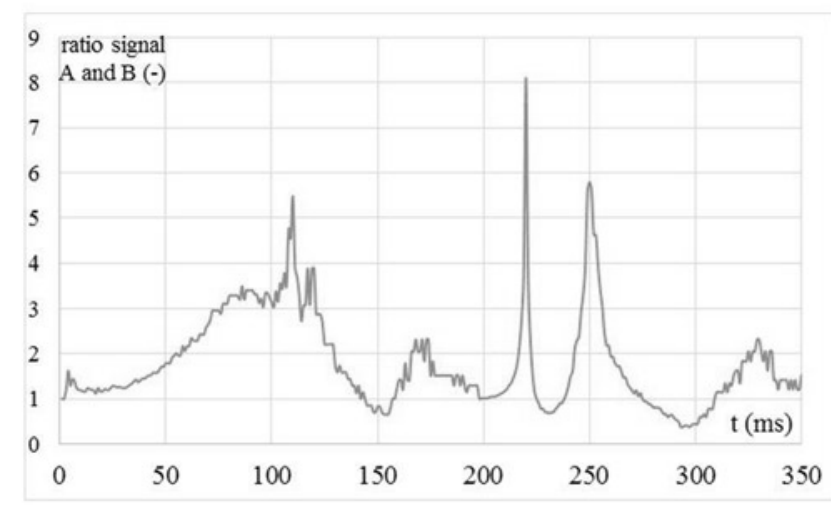

the windings, therefore it is useful to analyse differences in curves at pulse courses.

Splitting impulses into intervals ensure more detailed analysis. Fig. 16 shows values of amplitude coefficient related to particular ratio in time intervals. So as to analyse changes in damaged windings, we compared the behaviour of ratio in time (see Fig. 17). In interval from 1 to $150 \mathrm{~ms}$, maximum value of ratio is 5.47 , in time interval from 151 to $350 \mathrm{~ms}$, maximum of ratio is 8.11 . These results show and prove that there is a short-cut as well as deformation on windings of A phases.

\section{Conclusion}

The article shows the importance of knowledge of simulation and theoretical analysis of the axial and radial forces, which cause irreversible deformation of the transformer windings. Above analysis shows that it is necessary to know the value of short-circuit current, because it represents a danger for the transformer.

Calculated values of short-circuit currents from the simulation in MATLAB were fit into the formulas for calculation of radial and axial forces. The calculated values were applied to the model of the winding by means COMSOL Multiphysics, which output of the simulation was to determine the size and distribution of compressive stresses.

The application of the short-circuit current is not possible on the real transformer. We can diagnose transformer by means of frequency SFRA (Sweep Frequency Response Analysis) method or time response of windings by the high voltage impulse source. Both methods, SFRA method and method of impact test, indicate a significant sensitivity to a relatively small inter-thread deformation. These methods allow clearly analysing of the short circuit impact in the transformer windings.

Although the relation between the response course and state of winding is clear, it is very complicated. It is impossible to expect, that from the found out difference in the course of response we can consider the concrete damage of the winding. As the result of measurement we can only observe, that the state of winding changed. Such result of using of mentioned above methods could be useful in decision making, whether it is necessary to open and examine the transformer.

In order to obtain frequency response curve, there is a procedure to recalculate time response of the impulse measurement to the frequency domain. However, without IFRA method (Impulse Frequency Response Analysis) equipment, the calculation is demanding and requires oscilloscope with large sampling frequency and memory. Information and outcomes mentioned in the paper are the basis for future investigation, which will focus on enlarging the knowledge of and determining clear relation among the frequency domain, time domain and condition of the transformer windings.

These diagnostic methods of transformers considering the influence of short-circuit currents during the operation should be carried out to increase the reliability in real trouble-free process.

Acknowledgment
This work was partly supported by the R\&D operational program
Centre of Excellence of Power Electronics Systems and Materi-
als for their Components, No. OPVaV-2008/2.1/01-SORO, ITMS
26220120003 funded by the European Community and from the
statute tasks of the Lublin University of Technology, at the Faculty of
Electrical Engineering and Computer Science, 8620/E-361/S/2016
(S-28/E/2016), entitled "Researches of electrical, magnetic, thermal
and mechanical properties of modern electrotechnical and electronic
materials, including nanomaterials and electrical devices and their
components, in order to determination of suitability for use in elec-
trical engineering and to increase the efficiency of energy manage-
ment".
ment".

Fig. 17. Ratio of comparison signals $A$ and $B$ 


\section{References}

1. Hrabovcová V, et al. Measuring and Modelling of Electrical Machines. Zilina: EDIS. 2009; 335. ISBN 978-80-8070-924-2.

2. Fergestad R. Electromagnetic Forces in Core-type Transformers with Concentric Windings. CIGRE. no. 114, Part II.

3. Gutten M. Analysis of short-circuit currents in electrical equipment. Zilina: EDIS. 2011; 103. ISBN 978-80-554-0433-2.

4. Chitaliya G. H., Joshi S. K. Finite Element Method for Designing and Analysis of the Transformer - A Retrospective. International Conference on Recent Trends in Power, Control and Instrumentation Engineering PCIE 2013. Hyderabad 2013, India.

5. Heatcote MJ. The J \& P Transformer Book 13th edition. Chennai: ELSEVIER, 2007; 989. ISBN 978-0-7506-8164-3.

6. Gutten M. Diagnostic of distribution transformers by SFRA method. Przeglad Elektrotechniczny. 2007; 84(4): 144-146.

7. Glowacz A, Glowacz A, Glowacz Z. Recognition of Thermal Images of Direct Current Motor with Application of Area Perimeter Vector and Bayes Classifier. Measurement Science Review. 2015; 15(3): 119-126, https://doi.org/10.1515/msr-2015-0018.

8. Knaack W. The Mechanical Stressing of Transformer Windings Under Short-circuit. CIGRE. no. 135, Part II.

9. Kvasnička V, Procházka R, Velek J. Verification of method frequency characteristics in control room of distribution system Czech Republic. Conference Diagnostika 2005, Pilsen 2005, Czech Republic.

10. Sanka S. Transformers. 2nd edition. Bharat Heavy Electricals Limited Bhopal. New Dehli. 2003; 614. ISBN 978-0-17-048315-6.

11. Shayegani AA, Hassan O, Borsi H, Gockenbach E, Mosheni H. PDC Measurement Evaluation On Oil-Pressboard Samples. International Conference on Solid Dielectrics. 2014; 4: 50-62.

12. Heatcote M. J. J\&P. Transformer Book 13th Edition. GB: ELSEVIER. 2007; 974 p. ISBN-13 978-0-7506-8164-3.

13. Werelius P, Öhlen M, Adeen L, Brynjebo E. Measurement Considerations using SFRA for Condition Assessment of Power Transformers. International Conference on Condition Monitoring and Diagnosis, Beijing, China, April 21-24, 2008, https://oi.org/10.1109/ cmd.2008.4580428.

\author{
Miroslav GUTTEN \\ Daniel KORENCIAK \\ Matej KUCERA \\ Milan SEBOK \\ Faculty of Electrical Engineering \\ University of Zilina \\ 1 Univerzitna Str., 01001 Zilina, Slovakia
}

\section{Marek OPIELAK}

Faculty of Mechanical Engineering

Lublin University of Technology

ul. Nadbystrzycka 36, 20-618 Lublin, Poland

\section{Pawel ZUKOWSKI}

Tomasz N. KOLTUNOWICZ

Faculty of Electrical Engineering and Computer Science

Lublin University of Technology

ul. Nadbystrzycka 38a, 20-618 Lublin, Poland

E-mails: miroslav.gutten@fel.uniza.sk, daniel.korenciak@fel.uniza.sk, matej.kucera@fel.uniza.sk,milan.sebok@fel.uniza.sk,m.opielak@pollub.pl, p.zhukowski@pollub.pl, t.koltunowicz@pollub.pl 